\title{
Virtud y voluptuosidad: la figura de Epicuro en el Essai sur les règnes de Claude et de Néron, et sur les mours et les écrits de Sénèque de Diderot ${ }^{1}$
}

\begin{abstract}
Adrián Ratto
Resumen: La defensa que Diderot realiza de la filosofía de Epicuro en uno de sus últimos escritos, el Essai sur les règnes de Claude et de Néron, et sur les maurs et les écrits de Sénèque, parece alejarlo del objetivo que se había propuesto en ese escrito, a saber, defender la imagen de Séneca. El objetivo de este artículo es demostrar que, a pesar de lo que puede parecer en un primer momento, el problema no es más que aparente. A la luz de este asunto, el trabajo también examina otros dos temas que provocan tensiones en el texto y parecen debilitar su estructura. En un plano más general, el artículo arroja algunas luces acerca de la recepción de los trabajos de Epicuro y de Séneca en el siglo XVIII.
\end{abstract}

Palabras clave: Diderot - Epicuro - Séneca - voluptuosidad - virtud

\section{Virtue and voluptuousness: the Epicurus' image in Diderot's Essai sur les règnes de Claude et de Néron, et sur les mours et les écrits de Sénèque}

\begin{abstract}
Diderot's defense of Epicurus' philosophy in one of his last writings, Essai sur les règnes de Claude et de Néron, et sur les mours et les écrits de Sénèque, seems to distance him from the purpose he has in that work, namely, defending Seneca's image. The aim of this article is to show that, despite what it may appear at first, the problem is only apparent. In the light of this issue, the paper also examines two other themes that cause tensions in the text and jeopardize its structure. In a broader sense, the article sheds some light on the reception of Epicurus' and Seneca's works in the 18th century.
\end{abstract}

Keywords: Diderot - Epicurus - Seneca - voluptuousness - virtue

\footnotetext{
${ }^{1}$ Una versión preliminar de este trabajo fue presentada en el I Encontro Argentina-Brasil sobre estudos do século XVIII / I Encuentro Argentina-Brasil sobre estudios del siglo XVIII, que tuvo lugar en octubre de 2020 y fue organizado por la Associação Brasileira de Estudos do Século XVIII y la Asociación Argentina de Estudios del Siglo XVIII.

2 Adrián Ratto es doctor en Filosofía por la Universidad de Buenos Aires (UBA). Actualmente se desempeña como docente en la Facultad de Filosofía y Letras de dicha institución y como investigador adjunto en el Consejo Nacional de Investigaciones Científicas y Técnicas (CONICET). Dirección de correo electrónico: rattoadrian@gmail.com
} 


\section{Introducción}

En los $\iint 68$ y 69 de la Segunda parte del Essai sur les règnes de Claude et de Néron, et sur les maxurs et les écrits de Sénèque, uno de los últimos trabajos de Diderot, el autor, que se había propuesto en esa obra defender la imagen de Séneca, parece alejarse de su propósito, al referirse en términos positivos a una escuela, la epicúrea, rival a la que la tradición asocia al filósofo romano, la estoica. El objetivo de este artículo es demostrar que, a pesar de lo que puede parecer en un primer momento, el problema no es más que aparente.

Por otra parte, el texto, a partir del examen del lugar del epicureísmo en el escrito, pone de relieve otras tensiones que lo atraviesan y parecen debilitar su estructura, a saber, una serie de críticas a la filosofía de Séneca por parte de Diderot y un problema metodológico. En un plano más general, el artículo arroja algunas luces acerca de la recepción de los trabajos de Epicuro y de Séneca en el siglo XVIII.

La estructura del trabajo es la siguiente: en primer lugar (1), se reconstruyen los motivos que llevaron a Diderot a redactar el texto, se pone de relieve su carácter polémico y se examina la autocrítica que el filósofo realiza en el mismo; luego, (2), se analizan las alusiones que Diderot hace a Epicuro y su escuela en el escrito y se evalúa en qué medida su valoración positiva no contradice el resto de la obra; por último (3), se indagan, a partir de lo anterior, otras dos cuestiones que parecen amenazar el objetivo del libro.

\section{1) ¡Diderot contra sí mismo!}

El texto de Diderot tuvo dos ediciones, una en 1778 y la otra en 1782. La primera se publicó bajo el título de Essai sur Sénèque le philosophe, sur ses écrits et sur les règnes de Claude et de Néron, en el tomo VII de las Euvres de Sénèque, le Philosophe, traducidas por M. de La Grange y Jacques-André Naigeon, la segunda, como una obra independiente, bajo el título de Essai sur les règnes de Claude et de Néron, et sur les maurs et les écrits de Sénèque, pour servir d'introduction à la lecture de ce philosophe (de aquí en adelante Essai). Entre los motivos de la segunda edición se encontraba el de responder a las críticas que la primera había recibido, publicados, principalmente, en L'Année littéraire y en el Journal de Paris. Uno de esos cuestionamientos fue el de haber hecho una obra militante, polémica, antes que un tratado académico, el de haber hecho el trabajo de un "apologista" antes que el de un "historiador"3.

Diderot reproduce parcialmente y rechaza la objeción en el $\ 109$ de la Segunda parte de su escrito, en el que también da cuenta de otros cuestionamientos ${ }^{4}$. Sostiene que ha hecho precisamente lo contrario de lo que se lo acusa y que es una prueba de ello el hecho de "no

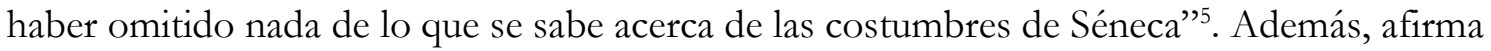
en las primeras páginas del texto que se propone "examinar sin parcialidad la vida y las obras de Séneca". La estructura de la obra parece, asimismo, alejar a Diderot de la objeción antes mencionada. El escrito está organizado a la manera de los trabajos académicos de la época, es decir, está dividido en dos partes, la primera, consagrada a la vida de Séneca, a la luz de

\footnotetext{
3 ANÓNIMO, "Belles Lettres", p. 97.

${ }^{4}$ DIDEROT, Essai sur les règnes de Claude et de Néron, p. 405.

${ }^{5}$ DIDEROT, Essai sur les règnes de Claude et de Néron, p. 405.

${ }^{6}$ DIDEROT, Essai sur les règnes de Claude et de Néron, p. 35.
} 
los relatos de los historiadores romanos Tácito y Suetonio, presentados en Annales y en $D e$ vita Caesarum, respectivamente, y la segunda, al análisis de sus obras.

Sin embargo, el trabajo parece ser algo más que un frío tratado académico, ajeno a la coyuntura social y política de la Francia del siglo XVIII. Entre los siglos XVI y XVIII la imagen del filósofo romano se inscribe en el marco de un neo-estoicismo y de un retorno del interés por la Antigüedad, en general, que emerge a la luz de un contexto político y religioso de luchas, sufrimiento e inquietud frente al cual el saber escolástico con sus luchas de facciones y sus vanas querellas se revelaba inútil ${ }^{7}$. En ese marco, Diderot redacta el trabajo por un encargo en 1777 del barón d'Holbach, quien le pide una vida de Séneca, para coronar la nueva edición de las obras completas de Séneca en la que estaban trabajando, en ese momento, algunos integrantes de su círculo, al que pertenecía el mismo Diderot. Como sostiene Jean Ehrard, la traducción de los escritos de Séneca realizada por M. de La Grange y Jacques-André Naigeon y el trabajo de Diderot deben ser vistos como parte de una estrategia de conjunto, que tuvo sus bases en el Système de la nature (1770) y La Morale universelle (1776) de d'Holbach, para presentar una moral laica, atea, independiente de los valores religiosos ${ }^{8}$. “ $¡ O h$, Séneca! Tú eres y serás por siempre, junto a Sócrates y todos los ilustres desdichados, junto a los grandes hombres de la Antigüedad, uno de los dulces lazos que me une a mis amigos", exclama Diderot ${ }^{9}$. Algunas páginas después, al comienzo del $\ 119$ del Primer libro, agrega: "es necesario reconocer que en muchas ocasiones los enemigos de nuestros filósofos se parecen increíblemente a los detractores de Séneca" ${ }^{10}$.

En efecto, el filósofo parece más preocupado por defender una causa que por hacer el trabajo de un erudito. No resulta llamativo, entonces, que, a pesar de conocer el latín, trabajara, en general, a partir de traducciones: aquella que el mismo La Grange había preparado para Les Euvres de Sénèque, pero también traducciones de versiones antiguas, como los dos volúmenes de las Euvres morales et mêlées de Sénèque, traducidas en 1595 por Simon Goulart. No es sorprendente, tampoco, que introdujera pasajes vinculados a la coyuntura, que poco tenían que ver con la obra o la vida de Séneca, como, por ejemplo, una serie de reflexiones acerca de la revolución norteamericana o de las críticas que recibió la Histoire des deux Indes de Raynal ${ }^{11}$. En cualquier caso, él mismo confiesa, finalmente, que su verdadero propósito es "vengar" a Séneca de sus críticos, tanto antiguos como modernos ("esos cobardes que han arruinado tu memoria [la memoria de Séneca]") y reconoce, hacia el final del libro, su falta de distancia con respecto a la figura del filósofo romano, el hablar "con ardor en favor de un filósofo [Séneca]"12.

La defensa gira, principalmente, en torno a una justificación del papel de Séneca en la corte de Nerón. Sobre la base de una identificación de "la virtud" con "la justicia", con el

\footnotetext{
${ }^{7}$ Para una visión de conjunto acerca de las diferentes interpretaciones de la figura de Séneca desde la Antigüedad hasta nuestros días, véase HEIL Y DAMSCHEN, Brill's Companion to Seneca: Philosopher and Dramatist, pp. 5395.

${ }^{8}$ EHRARD, "Pourquoi Sénèque?”, p. 6. El barón d'Holbach alude a la figura y las obras de Séneca en diferentes pasajes de su célebre Système de la nature, Holbach, Système de la nature, pp. 288, 318. Además de Diderot, el barón d'Holbach, Naigeon y La Grange, conformaron aquello que Jean Deprun llama el atelier Séneca los naturalistas franceses Jean d'Arcet (1724-1801) y Nicolas Desmarest (1725-1815), quienes colaboraron anotando la edición de las Naturales quaestiones, DEPRUN, "Diderot au travail", p. 19.

${ }^{9}$ DIDEROT, Essai sur les règnes de Claude et de Néron, p. 39.

${ }^{10}$ DIDEROT, Essai sur les règnes de Claude et de Néron, p. 210.

${ }^{11}$ DIDEROT, Essai sur les règnes de Claude et de Néron, pp. 355, 418.

${ }^{12}$ DIDEROT, Essai sur les règnes de Claude et de Néron, pp. 38, 39, 406.
} 
"bien general" ("no hay más que una virtud, la justicia"13), arguye, frente a aquellos que le reprochaban el haber vivido junto a un tirano, que hizo bien al permanecer al lado de Nerón, en la medida en que con sus acciones veló por el bienestar de sus amigos, familiares y de los ciudadanos en general: "cuanto más desordenado, ignorante, disoluto y feroz es el príncipe, más valioso es el papel del sabio comprometido" ${ }^{\text {". }}$. Valora, de este modo, la conducta del sabio que se compromete con los asuntos de la ciudad y lucha para modificar o, en todo caso, moderar o retrasar las extraviadas decisiones de los malos príncipes ${ }^{15}$. De la misma manera se expresa en diferentes pasajes del texto, como, por ejemplo, el $₫ 74$ de la Primera parte, donde, al hablar de la posición de Séneca en la corte de Nerón tras la muerte de Agripina, explica, ante quienes lo criticaban por no abandonar su cargo luego del crimen, que "era útil que permaneciera allí [junto a Nerón] por su familia, sus amigos, por los buenos ciudadanos" $"$.

La identificación de la virtud con la justicia, con la utilidad pública, atraviesa la obra de Diderot y hunde sus raíces en su Essai sur le mérite et la vertu (1745), un trabajo de juventud, que es, en realidad, una traducción anotada del libro An Inquiry Concerning Virtue or Merit (1699) del conde de Shaftesbury. Allí, sin embargo, ataca a Séneca. En efecto, en una nota al pie colocada al final del texto, acusa al filósofo romano de mantener un "vergonzoso silencio" ante los terribles actos cometidos por Nerón y de mostrarse más preocupado por "aumentar su riqueza" que por enseñar a su pupilo a ser un hombre virtuoso ${ }^{17}$. En cambio, en 1778/1782, tras señalar expresamente su pesar por esa crítica de juventud, presenta a Séneca como un hombre virtuoso, preocupado por sus conciudadanos de la Roma del siglo I d.C y amigos antes que por sí mismo ${ }^{18}$. ¿Cómo interpretar este desplazamiento?

Diderot se muestra en sus últimos años más "realista". Tomando distancia de la época en la que pensaba, dice, que era "más importante hablar bien que actuar bien"19, afirma en su madurez que prefiere "una bella acción” a una "bella página", al defensor de Calas,

${ }^{13}$ DIDEROT, Essai sur les règnes de Claude et de Néron, p. 344.

${ }^{14}$ DIDEROT, Essai sur les règnes de Claude et de Néron, p. 92. Vivir en la corte de un tirano no implica, por otra parte, explica Diderot, que el filósofo deba dejar de decir la verdad (p. 282). El filósofo francés, admirador de Sócrates y de Diógenes, sostiene que hacerlo sería "eternizar el reino de la ignorancia y la barbarie" (p. 282). Desde una visión pesimista de la historia, afirma, sin embargo, que en sus días "Diógenes no viviría en un barril, sino bajo un techo" (p. 53), en alusión a las dificultades para decir en su época la verdad directamente, sin velar de alguna manera el mensaje, tal como lo hacía la tradición de autores clandestinos de ese tiempo, a la que él mismo también perteneció. STAROBINSKI, Diderot, un diable de ramage, pp. 201-223 (cap. 8: "Diogène"). Sobre Diderot y la literatura clandestina, puede consultarse el dossier "Diderot et la littérature clandestine", a cargo de Geneviève Artigas-Menant, Antony McKenna y Pierre-François Moreau, publicado en el n. ${ }^{\circ} 19$ (2011) de La Lettre clandestine.

${ }^{15}$ DIDEROT, Essai sur les règnes de Claude et de Néron, pp. 93, 94.

${ }^{16}$ DIDEROT, Essai sur les règnes de Claude et de Néron, p. 140.

${ }^{17}$ DIDEROT, Essai sur le mérite et la vertu, p. 424.

${ }^{18}$ En el $\int 118$ del Primer libro del Essai, se puede leer: "un joven autor, a quien estimo y puedo dirigirme sin rodeos, ha publicado la crítica más lacónica y violenta que se haya hecho a Séneca (...) (p. 203)". Inmediatamente, luego de reproducir algunos pasajes de la nota al pie escrita por él mismo contra Séneca en el trabajo de 1745, exclama: "¿De dónde has tomado todo esto? ¿Sobre qué apoyas tus críticas? (...) juzgas al hombre de acuerdo a un modelo fantástico (...). Una vez que hayas luchado contra tí mismo, una vez que hayas sentido en el propio cuerpo la lucha del sabio, te sentirás avergonzado por las injurias que has lanzado contra el más virtuoso y, yo agregaría, el más desdichado de los hombres, si es que se puede unir la virtud a la desdicha" (p. 204). El pasaje se cierra con el reconocimiento por parte del autor de que se trata de una crítica a lo que él mismo había escrito en 1745: “¿Quién es ése que se refiere con esa vanidad a dos célebres personajes (...)? Soy yo mismo, yo mismo a la edad de veinte años (...) es a mí mismo a la edad de veinte años a quien, ahora, con más de sesenta, dirijo esta lección" (p. 205).

${ }^{19}$ DIDEROT, Essai sur les règnes de Claude et de Néron, p. 228. 
antes que al autor de Mahomet $^{20}$. En este mismo sentido, al comentar las Epistulae morales ad Lucilium, afirma que en lugar del erudito en soledad, alejado de los asuntos públicos, prefiere "al sabio en acción" 21.

Es posible pensar que, en el caso de Diderot, la experiencia que trae consigo el paso del tiempo ${ }^{22}$ y su participación en el círculo del barón de d'Holbach, entre otras cosas, puedan haberlo llevado, efectivamente, a interpretar en 1778/1782 la figura de Séneca de una manera diferente a la de 1745. En cualquier caso, se observan en el texto otras tensiones menos fáciles de elucidar. Una de ellas es la valoración positiva que se hace de la filosofía de Epicuro y del epicureísmo en general en la Segunda parte del libro. ¿No es la epicúrea una escuela rival a la estoica, con la que la tradición asocia a Séneca? A continuación, se examinará este aparente conflicto.

\section{2) En defensa de Epicuro y contra sus falsos discípulos}

En los $\iint 68$ y 69 de la Segunda parte del Essai, el autor hace una especie de apología del epicureísmo y ataca en duros términos al estoicismo. Estos apartados, que, con la excepción de algunos pasajes de un trabajo de Paolo Quintili ${ }^{23}$, no han logrado atraer aún el interés de los especialistas, pueden resultar llamativos, en la medida en que el editor de la Encyclopédie se había propuesto en el escrito, como se ha señalado en la sección anterior, realizar una defensa de la figura y los escritos de Séneca, a quien la tradición considera, en general, un representante de la filosofía estoica.

En cualquier caso, la alusión que Diderot hace a Epicuro y a sus discípulos en el Essai no es una referencia aislada en su obra. En efecto, ya había aludido de manera expresa o indirecta a Epicuro y a sus discípulos, tanto antiguos como modernos, en otros trabajos. En la entrada EPICURÉISME OU EPICURISME, publicada en el volumen V (1755) de la Encyclopédie, tras señalar que "nunca una filosofía fue tan mal comprendida y calumniada como la de Epicuro” y explicar en qué consisten los errores de las interpretaciones más comunes, a saber, considerar su filosofía como atea y a él como un "apologista del libertinaje", hace un resumen de los diferentes aspectos de su pensamiento y el de sus discípulos, poniendo especial atención en su materialismo atomista ${ }^{24}$. No duda en este texto, redactado sobre la base de la Historia critica philosophiae de Jakob Brucker, en afirmar que la vida de Epicuro estuvo indisociablemente ligada a "la virtud y a la temperancia" y que los integrantes de su secta fueron "personas muy honestas"25. También en Le Rêve de d'Alembert (1769) el lector encuentra el nombre de Epicuro, aunque allí la mayor influencia parece ser la de un hombre de su secta, Lucrecio, cuyo De rerum natura sirvió como base para el texto de Diderot. En este libro, el influjo se advierte, particularmente, en el terreno de la física, de la concepción de la naturaleza que presenta Diderot, en la que resuena el materialismo atomista de Epicuro y su

\footnotetext{
${ }^{20}$ DIDEROT, Essai sur les règnes de Claude et de Néron, p. 319. También se refiere a Voltaire en el \86 de la Segunda parte del Essai.

${ }^{21}$ DIDEROT, Essai sur les règnes de Claude et de Néron, p. 251.

22 Paso del tiempo alimentado, en el caso de Diderot, por los días que pasó como prisionero en el castillo de Vincennes, los problemas que sufrió como editor de la Encyclopédie y su desencanto con la emperatriz Catalina II de Rusia, entre otras cosas.

${ }^{23}$ QUINTILI, “Les Matérialistes anciens chez Diderot”, pp. 487-512.

${ }^{24}$ DIDEROT, "Epicuréisme ou epicurisme", pp. 779-785.

${ }^{25}$ DIDEROT, "Epicuréisme ou epicurisme”, p. 779.
} 
escuela $^{26}$. Como señala Alain Gigandet, no dejan de advertirse, no obstante, una serie de desplazamientos entre ese atomismo clásico y el materialismo vitalista de Diderot ${ }^{27}$. Algunos pocos años más tarde, en las notas que escribe al margen de la Lettre sur l'bomme et ses rapports de François Hemsterhuis durante su estadía en Holanda en 1773, vuelve a mostrar su interés por Epicuro y su escuela. Ante los ataques de Hemsterhuis a los materialistas, responde que Epicuro fue un "hombre sabio", que "Demócrito y Epicuro no eran ni hombres envilecidos ni hombres sin espíritu" y que los materialistas modernos "son hombres de bien" y "están lejos de creer que su opinión conduzca a la inmoralidad" ${ }^{28}$, retomando, en este último caso, la discusión acerca de la posibilidad de articular el ateísmo y la virtud, una controversia que atraviesa todo el siglo XVIII ${ }^{29}$.

Las alusiones que Diderot hace a Epicuro y sus discípulos en el Essai forman parte de una serie de reflexiones acerca de la naturaleza de la felicidad, que se desarrolla en los $\$ \int$ 67-72 de la Segunda parte del texto, en los que se ocupa de De vita beata de Séneca ${ }^{30}$. Frente al estoicismo, que condena al sabio a un alejamiento de la sociedad y excluye la voluptuosidad en su respuesta a esta cuestión, el editor de la Encyclopédie toma distancia, señalando que no se llega a ese corolario más que después de "una cadena de sofismas" 31 . Agrega, a continuación, que "la filosofía estoica es una especie de teología" y que "no conoce doctrina más alejada de la naturaleza que la de Zenón"32. En este marco se reivindica a Epicuro como el representante de una moral "sana" y "austera" 33.

Ahora bien, ¿no debilitan esta crítica al estoicismo y esta reivindicación de la figura de Epicuro la estructura de un trabajo cuyo principal objetivo es defender la figura de Séneca? La respuesta a esta cuestión parece ser negativa por dos motivos. Por una parte, la "apología del epicureísmo", que se hace a partir de la referencia positiva a Epicuro que el mismo Séneca presenta en el capítulo XIII de De vita beata, muestra a Epicuro como un hombre que no es esclavo de las pasiones, que supo, sin negar la voluptuosidad, encerrarla dentro de "los límites más estrechos" ${ }^{34}$. "Si se interroga al discípulo de Epicuro dirá que de todas las voluptuosidades la más dulce es la que nace de la virtud", exclama ${ }^{35}$. Por otra parte, el cuestionamiento al estoicismo alcanzaría a lo que Diderot denomina "estoicismo rigorista" o "zenonismo", pero no al "estoicismo moderado", con el que en general vincula a Séneca. En el $\int 13$ de la Primera parte, explica, al hablar de la formación del filósofo romano y de la influencia sobre su pensamiento de diferentes personajes y corrientes, que, si bien conoció a los "estoicos rigoristas", fue un "estoico moderado", es decir, un hombre capaz de articular

\footnotetext{
${ }^{26}$ DIDEROT, Le Rêve de D'Alembert, p. 130.

${ }^{27}$ GIGANDET, "Lucrèce vu en songe. Diderot, Le rêve de d'Alembert et le De rerum natura", pp. 416 y ss. A propósito de la figura de Lucrecio en la obra de Diderot, véase también Goulbourne, "Diderot and the Ancients", pp. 18-20. En cuanto a la recepción del atomismo antiguo en los siglos XVII y XVIII, pueden consultarse: WILSON, Epicureanism at the Origins of Modernity y el dossier "L'épicurisme des Lumières", dirigido por Anne Deneys-Tunney y Pierre-François Moreau y publicado en el n. 35 (2003) de Dix-buitième siècle.

${ }^{28}$ HEMSTERHUIS, Lettre sur l'homme et ses rapports. Avec le commentaire inédit de Diderot, pp. 139, 443, 441.

${ }^{29}$ Acerca de las críticas de aquellos que vinculaban el epicureísmo al ateísmo y la inmoralidad para atacar a les philosophes, desde el cardenal de Polignac, autor de un Anti-Lucretius, al abad Nicolas-Sylvestre Bergier, véase ALBERTAN-COPPOLA, "L'anti-épicurisme", pp. 309-318.

${ }^{30}$ DIDEROT, Essai sur les règnes de Claude et de Néron, p. 346.

${ }^{31}$ DIDEROT, Essai sur les règnes de Claude et de Néron, p. 347.

32 DIDEROT, Essai sur les règnes de Claude et de Néron, p. 348.

${ }^{33}$ DIDEROT, Essai sur les règnes de Claude et de Néron, p. 348.

${ }^{34}$ DIDEROT, Essai sur les règnes de Claude et de Néron, pp. 347, 348.

${ }^{35}$ DIDEROT, Essai sur les règnes de Claude et de Néron, p. 347.
} 
la austeridad del estoicismo con el hedonismo de los epicúreos y la preocupación por la virtud de Sócrates ${ }^{36}$.

Intenta alejar a Séneca de un camino que conduce a prácticas ascéticas y se oponen al bien general antes mencionado ${ }^{37}$. Pero, ¿no destruye también un hedonismo desenfrenado esa moral que se propone articular el interés particular con el general? Probablemente, así sea. En cualquier caso, no es ése, como se señaló, el tipo de hedonismo que Diderot atribuye a Epicuro y su escuela. No fueron más que sus "falsos discípulos" - en alusión a, probablemente, entre otros, Julien Offray de La Mettrie ${ }^{38}$ - los que, explica, interpretaron su doctrina de esa manera, los que "comprendieron mal" la idea de "voluptuosidad" 39.

De este modo, tomando distancia de un tipo de estoicismo, el rigorista, que conduce a una manera de actuar que rechaza, y de una mala comprensión del epicureísmo, la de sus falsos discípulos, puede decir que "no sería difícil conciliar a propósito de la moral a esas dos escuelas [epicureísmo y estoicismo]"40. A ese intento de conciliación se refiere, seguramente, cuando afirma, poco después: "después de dormir, medito y después de meditar, necesito alimentarme" ${ }^{41}$.

\section{3) Séneca, la moral estoica y algunas reflexiones metodológicas}

La apología del epicureísmo no parece, como se ha intentado mostrar en el apartado anterior, provocar un problema en la estructura del libro, pero saca a la luz otras cuestiones que pueden generar cierta perplejidad en el lector, a saber, las críticas que, por momentos, Diderot dirige al mismo Séneca y la incertidumbre que rodea, finalmente, al saber que el filósofo se propone apoyar.

El editor de la Encyclopédie, como hemos mencionado, intenta tomar distancia de una rama del estoicismo, a la que denomina rigorista o zenonismo, que, comprometida con una idea demasiado rígida de virtud, aleja al sabio de los asuntos públicos y, de este modo, del tipo de filosofía práctica que intenta defender. Como se señaló, busca alejar la imagen de Séneca de ese tipo de estoicismo y asociarlo a lo que llama estoicismo moderado. Sin embargo, Séneca parece, por momentos, no ajustarse a ese deseo. En efecto, al releer una de las cartas de Séneca a Lucilio, en la que el filósofo romano le aconseja exhortar a su amigo a que permanezca en "el reposo", en "el retiro", Diderot exclama que eso no es bueno para la

\footnotetext{
${ }^{36}$ DIDEROT, Essai sur les règnes de Claude et de Néron, p. 54.

${ }^{37}$ Sobre esta base se apoya también la crítica que dirige a Rousseau en los \$\$ 61-67 de la Primera parte del libro. Nos hemos ocupado de examinar esas críticas en RATTO, "Soledad y filosofía. Las críticas de Diderot a Rousseau en el Essai sur les règnes de Claude et de Néron, et sur les maurs et les écrits de Sénèque”, pp. 45-60.

38 Ataca a La Mettrie, que había publicado en 1748 un Anti-Sénèque, en el $\int 6$ de la Segunda parte del texto. A propósito de esas críticas, véase QUINTILI, Matérialismes et Lumières. Philosophies de la vie, autour de Diderot et de quelques autres 1706-1789, pp. 125-144 (cap. 3: "Lectures matérialistes du stö̈cisme au XVIIIe siècle: Diderot et La Mettrie").

${ }^{39}$ DIDEROT, Essai sur les règnes de Claude et de Néron, p. 348. Diderot, por otra parte, aprovecha la ocasión para trazar un paralelismo entre las palabras "voluptuosidad" e "interés", a propósito de lo que sucedió como consecuencia de -lo que él considera- su mala interpretación: "la palabra voluptuosidad (voluptê), mal comprendida, convirtió a Epicuro en una persona detestable, así como la palabra interés (intérêt), mal comprendida, provocó el murmullo de los hipócritas y los ignorantes contra un filósofo moderno” (p. 348). Se refiere, seguramente, en el último caso, a La Rochefoucauld.

${ }^{40}$ DIDEROT, Essai sur les règnes de Claude et de Néron, p. 347. Las cursivas son nuestras.

${ }^{41}$ DIDEROT, Essai sur les règnes de Claude et de Néron, p. 348.
} 
sociedad y que hay en el estoicismo un "espíritu monacal" que le desagrada ${ }^{42}$. Asimismo, al analizar el tratado De ira de Séneca, luego de constatar que el filósofo estoico niega la naturalidad de la cólera, incluso en casos como el violento asesinato de un ser querido, exclama: “Cómo Séneca? (...) ¿No? Tú me pides algo imposible" ${ }^{43}$. Es similar lo que se advierte en el comentario al libro V de De constantia sapientis. Allí, Diderot coloca a Séneca entre los estoicos que él califica como "rigoristas" y, luego de contar que Stilpon después del asalto a su ciudad y de haber perdido a su mujer y sus hijas había dicho que no había perdido nada y que Séneca había alabado la actitud de Stilpon, reacciona: "no lo disimularé, las palabras de Stilpon y el comentario de Séneca me indignan (...). Si tú no has perdido nada, es porque te habías alejado inexplicablemente de todo lo que es querido a los hombres. Si esas cosas no están adheridas al estoico como su vestimenta, entonces yo no soy estoico y me alegro de no serlo (...)"44.

¿Cómo interpretar estas objeciones a Séneca? ¿Se contradice Diderot? ¿Abandona el objetivo principal de su libro? No parece ser así. Las críticas sólo aparecen en los momentos en los que el filósofo romano se aparta de la figura del sabio comprometido con los asuntos de la ciudad, que Diderot busca instalar. Probablemente, se trate de una estrategia. Después de todo, él mismo había dicho que juzgaría a Séneca "con imparcialidad" y que no evitaría indicar "sus debilidades" o "contradecirlo" cuando fuera necesario ${ }^{45}$. Se podría pensar que, de esta manera, el autor buscó dar la impresión de ser un juez "neutral” y, de ese modo, otorgar mayor peso a su defensa.

En cualquier caso, a la luz de esto pueden surgir otras preguntas a las que resultaría menos sencillo responder: ¿cómo alcanzó Diderot el conocimiento acerca de la vida y las obras Séneca que presenta en el texto? ¿Sobre qué apoya sus afirmaciones? ¿Por qué su estoicismo no sería, en general, el mismo que el de Zenón? Como ya se indicó, el autor considera que la vida y los escritos del autor de De tranquillitate animi han sido mal interpretados y sostiene que, por el contrario, su lectura es "más sólida" que la de los "detractores" de Séneca e incluso de la que él mismo realizó en su juventud ${ }^{46}$. Con el fin de acercarse, entonces, a la verdad no se ocupa solamente de releer los escritos del filósofo romano ("he leído y releído..."), sino también de comprender su época y de examinar su "vida privada", es decir, "su educación", "su carácter", "sus inclinaciones, "sus gustos", etc. ${ }^{47}$. Los "secretos de la vida privada" muestran, dice Diderot, que Séneca era, entre otras cosas, un hombre "frugal" y "austero"

\footnotetext{
${ }^{42}$ DIDEROT, Essai sur les règnes de Claude et de Néron, p. 251.

${ }^{43}$ DIDEROT, Essai sur les règnes de Claude et de Néron, p. 316.

${ }^{44}$ DIDEROT, Essai sur les règnes de Claude et de Néron, p. 374.

${ }^{45}$ DIDEROT, Essai sur les règnes de Claude et de Néron, pp. 35, 229.

${ }^{46}$ DIDEROT, Essai sur les règnes de Claude et de Néron, p. 182.

${ }^{47}$ DIDEROT, Essai sur les règnes de Claude et de Néron, pp. 184, 242.

48 DIDEROT, Essai sur les règnes de Claude et de Néron, pp. 229, 289, 303. "El hombre de genio es conocido por la posteridad, el hombre es ignorado. ¿Qué sabemos de Homero, de Arquímedes, de Demóstenes, de Eurípides o de Sófocles? (...). Así como nuestros sobrinos deberán a Moréri, a Bayle, a Chaufepié, a Marchand, a Fontenelle, a d'Alembert, a Condorcet y a nuestra Academia francesa el conocimiento útil de las virtudes o los defectos domésticos que volvieron agradable o penoso el trato con los hombres célebres cuyas obras admirarán, nosotros lo debemos a Plutarco y a algunos otros biógrafos de la Antigüedad”, afirma (pp. 185, 186). Muriel Brot pone de relieve la importancia que Diderot otorga en el texto a un género, el de las "vidas", considerado menor entre los historiadores en la época, consagrados a la historia de los reyes y las guerras, véase BROT, "Diderot et les vies privées de Sénèque, Claude et Néron", pp. 57-64. La autora muestra que Diderot en el Essai recurre también a otros géneros considerados menores en esos tiempos, tales como la "anécdota" y el
} 
representación "verdadera" en el caso de este trabajo de Diderot o, como él dice, más sólida que las otras?

No parece que se pueda dar una respuesta completamente positiva a esta última pregunta por diferentes razones. En primer lugar, establecer los hechos no es una tarea sencilla. Habiendo lagunas entre los documentos, a menudo los textos de las autoridades, a las que se debe recurrir para reconstruir la imagen de un personaje histórico, son alcanzados por el "eco del rumor popular" o llenan dichas lagunas con absurdas conjeturas para "dañar, calumniar, difamar a los grandes hombres..." ${ }^{49}$. Pero, aun si se establecen adecuadamente los hechos, los problemas persisten. En efecto, es necesario interpretar esos hechos y, para eso, dice el filósofo, se debe tener en cuenta las circunstancias, es decir, no se debe juzgarlos fuera de su contexto. No se puede comprender adecuadamente la vida de Séneca si no se la enmarca en su época, en las cortes de Claudio y de Nerón: "se juzgará mal la posición y la conducta de gente honesta [Séneca y Burro] si se olvida a qué príncipe se enfrentaban..." ${ }^{50}$. Para eso, es necesario conocer, entre otras cosas, señala, las "intrigas secretas (...) las maquinaciones, los movimientos, los caracteres, las miradas, los intereses, los temores, las esperanzas, los proyectos, que cambian con las circunstancias, y las circunstancias, que cambian de un día a otro" ${ }^{51}$. Ahora bien, ¿cómo hacer para tener un conocimiento fidedigno de estos aspectos? ¿Cómo hacer para conocer "el tono", "la mirada" o "la consternación en el rostro de Séneca"? ${ }^{52}$. Finalmente, en cuanto a la lectura de las obras de Séneca, ¿es posible realizar una interpretación definitiva? Diderot denuncia a aquellos que "no han leído" sus obras o que "las han leído con prejuicios" 53 . No obstante, reconoce que su obra es el producto de "lecturas múltiples" y que "no relee las obras de Séneca sin advertir que no las ha leído aún lo suficiente" 54 . "Leo, converso, interrogo o respondo", dice y poco después agrega, dirigiéndose al lector, que éste "no tardará en darse cuenta de que es tanto su alma lo que describe como la de los personajes que se ofrecen a su relato" 55 .

El filósofo advierte que si el historiador se permite "agregar o quitar algo al relato histórico, ya no hay verdad ni falsedad" 56 . Sin embargo, eso es, precisamente, lo que hace: selecciona, añade y confunde a Séneca, por momentos, consigo mismo y a la Roma del siglo I d.C. con la Francia del siglo XVIII. Su lectura no parece menos arbitraria que cualquier otra. Él mismo confiesa que no se aborda de la misma manera "un acto que deshonra a la humanidad" que una acción "bella, noble y grande"; que es lícito librarse a "todo tipo de

\footnotetext{
“elogio" (pp. 59 y ss.). La justificación de la biografía se inscribe en un movimiento que desde los siglos XVI y XVII discute la preeminencia de la historia militar y política, véase GUION, Du bon usage de l'bistoire: histoire, morale et politique à l'âge classique.

${ }^{49}$ DIDEROT, Essai sur les règnes de Claude et de Néron, pp. 138, 143.

${ }^{50}$ DIDEROT, Essai sur les règnes de Claude et de Néron, p. 139.

51 DIDEROT, Essai sur les règnes de Claude et de Néron, pp. 96, 97.

52 DIDEROT, Essai sur les règnes de Claude et de Néron, p. 139.

53 DIDEROT, Essai sur les règnes de Claude et de Néron, p. 400.

${ }_{54}$ DIDEROT, Essai sur les règnes de Claude et de Néron, pp. 35, 240.

55 DIDEROT, Essai sur les règnes de Claude et de Néron, p. 35. Se podría pensar que el texto es, en cierto modo, autobiográfico y que el filósofo encuentra aquí la oportunidad de, entre otras cosas, justificar su papel junto a la emperatriz Catalina II de Rusia, así como de adelantarse a la publicación del escrito autobiográfico de Rousseau (Les Confessions), cuya publicación, que estimaba inminente al momento de la primera edición del Essai, lo inquietaba. Elena Russo considera que ésta es la principal clave de lectura del Essai, véase RUSSO, "Slander and Glory in the Republic of Letters: Diderot and Seneca Confront Rousseau", pp. 1-12.

${ }^{56}$ DIDEROT, Essai sur les règnes de Claude et de Néron, p. 139.
} 
conjeturas" para "exculpar" a un personaje ilustre ${ }^{57}$. Será un "mal juez", dice más adelante, quien no tenga un "doble tacto", ya que "la historia de los tiempos calamitosos no se escribe de la misma manera que la de los reinados venturosos"58. La historia parece ser, para Diderot, filosófica y política -como reza el título del trabajo del abate Raynal (Histoire philosophique et politique...), en cuya redacción colaboró- antes que factual ${ }^{59}$.

En este marco, la conclusión del Essai resulta menos desconcertante de lo que puede llegar a ser en un primer momento. Allí, en el $\$ 110$ de la Segunda parte del libro, sostiene que "los resultados que arrojan los hechos son limitados" y que, por lo tanto, es inevitable tener que apelar en el terreno de la historia a "infinitas conjeturas" ${ }^{60}$. Además, pone en entredicho la propia imagen de Séneca que ha intentado construir en el resto del texto:

Luego de tantas lecturas enfrentadas (...), decidme, lector, ¿cuál debe ser la conclusión? ¿Séneca y Burro fueron personas honestas o viles cortesanos? ¿Séneca fue un hombre de genio o no fue más que un falso bel esprit? ¿Habló acerca de la virtud con conocimiento o como un hipócrita? (...) ¿Conozco o no mi propia lengua? ¿Soy un razonador o un sofista? ¿Tiene mi discurso algún tipo de solidez o no es más que una frívola declamación? ¿'Tiene o no mi pensamiento consistencia e ideas originales? ¿He hecho un buen o un mal libro? (...) Convenid, lector, que tú no sabes nada acerca de eso, pero nada en absoluto ${ }^{61}$.

\section{A modo de conclusión}

Se ha intentado demostrar en este trabajo que la valoración positiva que Diderot realiza en el Essai de la filosofía de Epicuro (2) no provoca tensiones en el texto, ya que no ve en el epicureísmo y el estoicismo escuelas rivales -en cualquier caso, en el tipo de epicureísmo y estoicismo que le interesa defender, que no son ni el hedonismo desmesurado de los falsos discípulos de Epicuro ni la virtud impracticable de Zenón-, sino todo lo contrario. Esto, además, arroja algunas luces acerca de la recepción de las filosofías de Epicuro y de Séneca en el siglo XVIII. Este último tema, no obstante, desborda, sin dudas, los límites de este trabajo.

Por otra parte, el análisis del lugar que se otorga a la filosofía de Epicuro en el escrito saca a la luz dos problemas cuya articulación con el propósito principal del libro de Diderot parece menos sencilla (3). Por un lado, se ha mostrado que la defensa de la imagen de Séneca realizada por el editor de la Encyclopédie no impide que deslice también contra su filosofía una serie de cuestionamientos, algo que ha sido con frecuencia pasado por alto por los

\footnotetext{
${ }^{57}$ DIDEROT, Essai sur les règnes de Claude et de Néron, p. 82.

${ }^{58}$ DIDEROT, Essai sur les règnes de Claude et de Néron, p. 423.

59 Sobre este aspecto de la obra de Diderot, véase el reciente trabajo de D’ANTUONO, "Diderot et sa conception innovante de l'histoire utile, transfrontalière et rétrospective", p. 285-304.

${ }^{60}$ DIDEROT, Essai sur les règnes de Claude et de Néron, p. 431.

${ }^{61}$ DIDEROT, Essai sur les règnes de Claude et de Néron, pp. 430, 431. Las cursivas son nuestras. Acerca de la relación entre el autor y el lector en los escritos históricos del siècle des Lumières, especialmente en los trabajos de Diderot, véase PENKE, "La représentation de l'énonciateur et du destinataire dans le discours historique", pp. 517 y ss. Penke sostiene que el carácter militante de las obras históricas de la época llevó a menudo a los autores a ensayar diferentes estrategias, como, por ejemplo, unir de manera ficticia sus voces a las de los lectores, con el fin de conseguir la aceptación del contenido de sus escritos (p. 218).
} 
especialistas $^{62}$. Por otro lado, se han puesto de relieve una serie de cuestiones de índole metodológica a propósito de las herramientas con las que cuenta el filósofo para alcanzar el saber acerca de la vida y las obras de Séneca que pretende defender. Se puede pensar, tal vez, que el primer problema no es más que aparente si se considera esas críticas a Séneca como parte de una estrategia del autor para persuadir al lector, velando el carácter militante de su obra. La superación del segundo resulta, en cualquier caso, más difícil de conseguir, desde el momento en que los problemas metodológicos mencionados parecen socavar las bases sobre las que debería apoyarse el tipo de saber que Diderot se había propuesto presentar en el libro.

\section{Referencias bibliográficas}

ALBERTAN-COPPOLA, S. "L'anti-épicurisme”. In: Dix-buitième siècle, n 35, pp. 309-318, 2003.

ANONIMO. "Belles Lettres". In: Journal de Paris, pp. 97-99, 1779.

BROT, M. “Diderot et les vies privées de Sénèque, Claude et Néron”. In: Écrire l’histoire, vol. 17, pp. 57-64, 2017.

D'ANTUONO, G. "Diderot et sa conception innovante de l'histoire utile, transfrontalière et rétrospective". In: Libertinage et philosophie à l'époque classique (XVIe-XVIIIe siècle), n 17, pp. 285-304, 2020.

DEPRUN, J. "Diderot au travail”. In: Cuures complètes de Diderot. Ed. Jean Fabre, Herbert Dieckmann, Jacques Proust y Jean Varloot. París: Hermann, vol. 25, pp. 19-26, 1986.

DIDEROT, D. Essai sur les règnes de Claude et de Néron, et sur les mours et les écrits de Sénèque. Ed. Annette Lorenceau, prefacio de Jean Ehrard e introducción y comentarios de Jean Deprun. In: CEuvres complètes de Diderot. Ed. Jean Fabre, Herbert Dieckmann, Jacques Proust y Jean Varloot. París: Hermann, vol. 25, pp. 1-440, 1986.

Essai sur le mérite et la vertu. Ed. Paolo Casini y John Spink. In: CEuvres complètes de Diderot. Ed. Jean Fabre, Herbert Dieckmann, Jacques Proust y Jean Varloot. París: Hermann, vol. 1, pp. 266-428, 1975.

Le Rêve de D'Alembert. Ed. Jean Varloot y Georges Dulac. In: CEuvres complètes de

Diderot. Ed. Jean Fabre, Herbert Dieckmann, Jacques Proust y Jean Varloot. París: Hermann, vol. 17, pp. 25-209, 1987.

"Epicuréisme ou epicurisme". In: D. Diderot y J. d'Alembert (eds.), Encyclopédie on Dictionnaire raisonné des sciences, des arts et des métiers par une société des gens de lettres. Briasson / David / Le Breton / Durand: París, vol. V, pp. 779-785, 1755.

${ }^{62}$ GATEFIN, Diderot, Sénèque et Jean-Jacques: Un dialogue à trois voix, p. 7; MASSEAU, "L'enjeu d'une polémique: la figure de Sénèque dans l'Essai sur les règnes de Claude et de Néron", p. 149. 
EHRARD, J. "Pourquoi Sénèque?”. In: Euvres complètes de Diderot. Ed. Jean Fabre, Herbert Dieckmann, Jacques Proust y Jean Varloot. París: Hermann, vol. 25, pp. 3-18, 1986.

GATEFIN, E. Diderot, Sénèque et Jean-Jacques: Un dialogue à trois voix. Amsterdam: Rodopi, 2007.

GIGANDET, A. 'Lucrèce vu en songe. Diderot, Le rêve de d'Alembert et le De rerum natura". In: Revue de métaphysique et de morale, $\mathrm{n}^{\circ} 35$, pp. 415-427, 2002/3.

GOULBOURNE, R. "Diderot and the Ancients". In: J. Fowler (ed.), New Essays on Diderot. Cambridge: Cambridge University Press, pp. 13-30, 2011.

GUION, B. Du bon usage de l'bistoire: histoire, morale et politique à l'âge classique. París: Honoré Champion, 2008.

HEIL, A. y DAMSCHEN, G. (eds.). Brill's Companion to Seneca: Philosopher and Dramatist. Leiden: Brill, 2013.

HEMSTERHUIS, F. Lettre sur l'homme et ses rapports. Avec le commentaire inédit de Diderot. Ed. Georges May. New Haven: Yale University Press, 1964.

HOLBACH, P. H. T. Système de la nature. Londres: s. n., vol. 1, 1770.

MASSEAU, D. 'L'enjeu d'une polémique: la figure de Sénèque dans l'Essai sur les règnes de Claude et de Néron". In: Diderot Studies, vol. 32, pp. 149-164, 2012.

PENKE, O. "La représentation de l'énonciateur et du destinataire dans le discours historique". In: Dix-buitième siècle, vol. 32, pp. 503-520, 2000.

QUINTILI, P. "Les Matérialistes anciens chez Diderot”. In: M. Benítez et al. (eds). Materia actuosa: Antiquité, Âge classique, Lumières. Mélanges en l'honneur d'Olivier Bloch. París: Champion, pp. 487-512, 2000.

Matérialismes et Lumières. Philosophies de la vie, autour de Diderot et de quelques autres $1706-$ 1789. París: Honoré Champion, 2009.

RATTO, A. "Soledad y filosofía. Las críticas de Diderot a Rousseau en el Essai sur les règnes de Claude et de Néron, et sur les maurs et les écrits de Sénèque". In: Revista de Filosofía, vol. 40, n 1 , pp. 45-60, 2015.

RUSSO, E. "Slander and Glory in the Republic of Letters: Diderot and Seneca Confront Rousseau". In: Republics of Letters, vol. 1, no 1, pp. 1-12, 2009.

STAROBINSKI, J. Diderot, un diable de ramage. París: Gallimard, 2012.

WILSON, C. Epicureanism at the Origins of Modernity. Oxford: Oxford University Press, 2008. 